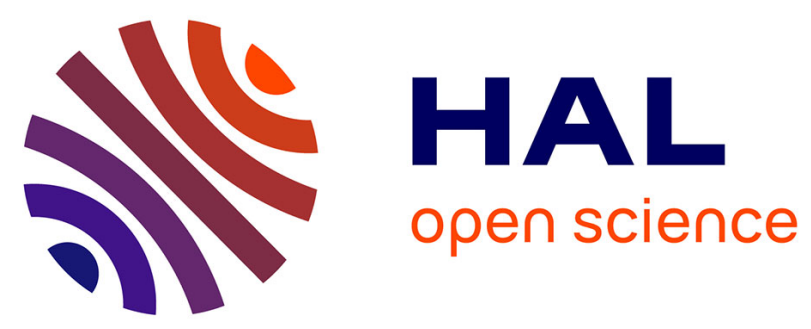

\title{
SURFACE EXTENDED X-RAY ABSORPTION FINE STRUCTURE STUDY ON (2x1) OXYGEN ON Ni(110)
}

U. Döbler, L. Wenzel, D. N. Arvanitis, K. Baberschke

\section{To cite this version:}

U. Döbler, L. Wenzel, D. N. Arvanitis, K. Baberschke. SURFACE EXTENDED X-RAY ABSORPTION FINE STRUCTURE STUDY ON (2x1) OXYGEN ON Ni(110). Journal de Physique Colloques, 1986, 47 (C8), pp.C8-473-C8-478. 10.1051/jphyscol:1986889 . jpa-00226220

\section{HAL Id: jpa-00226220 https://hal.science/jpa-00226220}

Submitted on 1 Jan 1986

HAL is a multi-disciplinary open access archive for the deposit and dissemination of scientific research documents, whether they are published or not. The documents may come from teaching and research institutions in France or abroad, or from public or private research centers.
L'archive ouverte pluridisciplinaire HAL, est destinée au dépôt et à la diffusion de documents scientifiques de niveau recherche, publiés ou non, émanant des établissements d'enseignement et de recherche français ou étrangers, des laboratoires publics ou privés. 


\title{
SURFACE EXTENDED X-RAY ABSORPTION FINE STRUCTURE STUDY ON ( $2 \times 1)$ OXYGEN ON Ni(110)
}

\author{
U. DÖBLER $(1)$, L. WENZEL, D. ARVANITIS and K. BABERSCHKE \\ Institut für Atom- und Festkörperphysik, Freie Universität \\ Berlin, Arnimallee 14, D-1000 Berlin 33, F.R.G.
}

\begin{abstract}
Resumé: - La chemisorption de $\leq 1 \mathrm{~L}$ d'oxygene à $470 \mathrm{~K}$ sur la surface ouverte (110) du $\mathrm{Ni}$ donne une surstructure $(2 \times 1)$ en DEL. Ceci est admis d'être du àune reconstruction induite pour l'adsorbat. on a trouvé que les distances $\mathrm{O}-\mathrm{Ni}$ premier et second voisins sout 1.85(3) et $1.96(8)$ \& respectivement. La détermination de si petites differences aux Iongueurs de liason est rendue possible grace à la polarisation lineaire du champ électrique E. Par le rapport des amplitudes pour differents angles azimutaux et polaire la geometrie d'adsorption est trouvée d'êtré sur un "long bridge" site suivant [100], l'atome d'o se trouvant $0.56 \AA$ au dessus du plan determiné par le centre des atomes de $\mathrm{Ni}$ de la première couche. La surface de $\mathrm{Ni}$ se reconstruit suivant le modele "saw tooth". Un deusième maximum de la transformée de Fourier pour $\mathrm{E}$ suivant [001] est discuté. Les modeles de reconstruction sont discutés et comparés avec le systeme o(2x1) sur du $\mathrm{Cu}(110)$. Un calcul de diffusion multiple au voisinage du seuil d' adsorption (NEXAFS), mesuré sur le même échantilion est trouvé an accord avec le résultat de 1' analyse SEXAFS.
\end{abstract}

Abstract: - Chemisorption of $\leq 1 \mathrm{~L}$ oxygen on the open Ni(110) face at $470 \mathrm{~K}$ results in a $(2 \times 1)$ LEED pattern. This is believed to be originated by an adsorbate induces reconstruction of the $\mathrm{Ni}$ substrate. The $\mathrm{O}-\mathrm{Ni}$ first and second nearest neighbour distances habe been determined to be $1.85(3) \&$ and $1.96(8) \AA$, respectively. A determination of such small differences in bondlength is possible due to the search light character of the linear polarization. From the amplitude ratios for different azimuthal and polar angles of incidence one determines the adsorption geometry to be a bridge site along [100] and the 0 atom sitting 0.56 \& above the midpoint of the first layer Ni atoms. The Ni substrate is reconstructed into a saw tooth model. A second peak in the Fourier transform for $\overrightarrow{\mathrm{E}}$ parallel to [001] is analysed. The models for reconstruction are discussed and compared with o(2x1) on $\mathrm{Cu}(110)$. A full multiple scattering calculation of the near edge x-ray absorption fine structure (NEXAFS) measured on the same sample agrees with the SEXAFS analysis.

\section{Introduction}

The submonolayer coverage of oxygen $(2 \times 1)$ on the reactive surface of $\mathrm{Ni}(110)$ has been investigated by numerous techniques. However, the microscopic picture of the site of chemisorption remains controversal. Slightly less than 1 Langmuir $\left(10^{-6}\right.$ Torr:sec) is needed for chemisorption of half a monolayer and for a chemically induced reconstruction into a $(2 \times 1)$ superstructure. This system allows some comparison with

(1) Siemens-Systemtechnik, Nonnendammallee 101, D-1000 Berlin 13, F.R.G. 
$\mathrm{O}(2 \times 1)$ on $\mathrm{Cu}(1,10)$. For both, a unicue cetermination of the adsorption site and of the local structure including vertical and horizontal relaxation of the substrate surface layer is of interest. On theoretical grounds there still remain several open questions: What drives the chemically induced reconstruction? The forces will be of short range (first and second neighbours only). Does this imply a change of $n . n$. coorcination number and symmetry with respect to the unperturbed (110) surface of the fcc lattice? We strongly want to distinguish between temperature driven reconstructions (of clean surfaces, for example) and the "local" mechanism of chemisorption. For the latter question the chemisorption binding energies for all three surfaces (100), (111), and $(110)$ of $\mathrm{O}$ on $\mathrm{Ni}$ would be useful. Unfortunately only a polycristal.line average of 4 to $5 \mathrm{eV}$ is known. At present, theory is not able to calculate reliably the small changes of the binding eneray (few tenths of an $\mathrm{eV}$ for different faces), the effect of a different coordination number and its consequences for the local bonding geometry. A further question remains open: How is the difference in bulk oxidation for $\mathrm{CuO}, \mathrm{Cu}_{2} \mathrm{O}$ and $\mathrm{NiO}$ explained? What causes in ExAFS the large difference in pahse shift for O-Ni backscatterer with respect to C-Cu backscattering?

The present SEXAFS work adds some more experimental evidence for the bonding geometries. In particular for $\mathrm{O}(2 \times 1)$ on $\mathrm{Ni}(110)$ recent scanning-tunneling microscopy (STM) experiments $/ 1$ / indicate a "saw tooth" type of reconstruction and $(2 \times 1)$ islands with $\tilde{n} 100$ oxygen atoms. Conseguently we have used the identical Ni single crystal of the IBM-group and followed their procedure of oxygen-dosing. The details of the experiment are discussed in Ref. $/ 2 /$. In Sec. II. we summarize the analysis of $\mathrm{n} . \mathrm{n}$. configuration. In sec. III: we discuss a second peak " $B$ " in the Fourier transform for $E$ parallel [oo1]. This is attributed to the backscattering of adjacent o-atoms. A different mean free path for the photoelectron wave above the surface will be used. In Sec. IV. we compare $\mathrm{O} / \mathrm{Ni}$ analysis with recent SEXAFS work for $O(2 \times 1)$ on $\mathrm{Cu}(110)$ by Bader et al. /3/. Finally in Sec. V a summary and a comparison with a full multiple scattering calculation and our Near Edge X-ray Absorption Structure (NEXAFS) will be given.

\section{Local bonding geometry of the o atoms}

Fig. 1 shows the EXAFS Oscillations above the $O$ K-edge for different azimuthal angle $\phi$ (a: $E / /[110]$ and $b: E / /[001])$ and for a polar angle of incidence of $\theta=45^{\circ}$. The spectrum in $\mathrm{Fig}$. $1 \mathrm{~b}$ with an edge jump of approx. 6\% for effectively $0.35 \mathrm{ML}$ is one with largest sional-to-noise ratios for submonolayer SEXAFS. This also results in a small noise in the Fourier transform (Fig. 2). The amplitude reduction for $\mathrm{E} / /$ [110] with respect to $\mathrm{E} / /$ [001] $i \mathrm{~s}$ a factor of 5. However, the distance determined by using the experimental phase shift from bulk Nio is only slightly larger (1.96 $\AA)$ for the former, compared to $1.85 \AA$ for the latter. Such a smali change of $\Delta R \approx 0.1 \AA$ can only be determined by virtue of the azimuthal angular dependence, see Fig. 2. This $\phi$-dependence and the two values for $R$ strongly favors a long bridge site with the o-atom sitting above the first layer of $\mathrm{Ni} / 4 /$. In Fig. 3, 3 modelstructures are drawn. Ali have in common the bridge site position. The very sensitive point in a SEXAFs experiment is that for the saw tooth model in [110] direction oxygen has only one backscatterer, whereas for missing row and buckled surface in the [001] and [110]' direction there remain always 2 backscatterers. Without a changé of $R$ or $\cos ^{2} \alpha$ one expects a reduction in the SEXAFS amplitude by a factor of 2 in going from $\phi=0^{\circ}$ to $\phi=90^{\circ}$. Taking into account the change in $R$, in $\cos ^{2} \alpha$ and using an effective mean Eree path of $\lambda \approx 5 \AA$ one finds precisely the experimental value of 0.19 , shown in Táb. 1 . 
A detailed simulation of the EXAFs oscillation taking into consideration vertical relaxation and tilt of the oxygen with respect to the

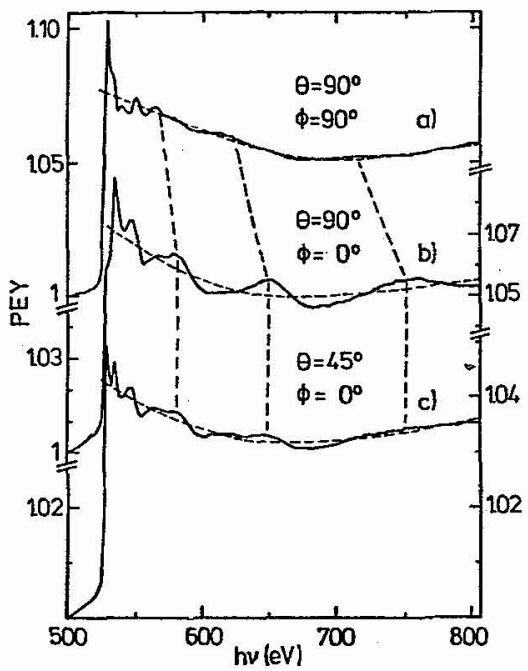

Fig. 1: Partial electron yield (using 350 eV retarding voltage) after normalization. $\phi=0$ corresponds to the [001] axis.

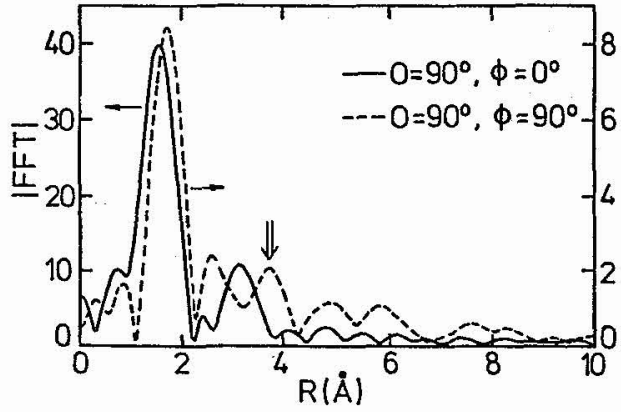

Fig. 2: Fouriertransform of spectrum in Fig. 1 a and $\mathrm{b}$. Right hand scale for the dashed line.

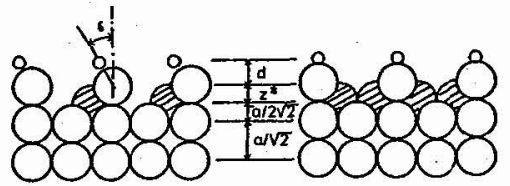

$\rightarrow[110]$

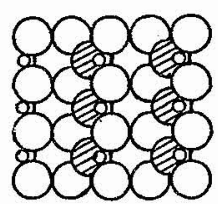

saw tooth

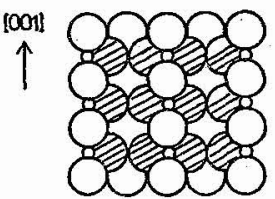

missing row
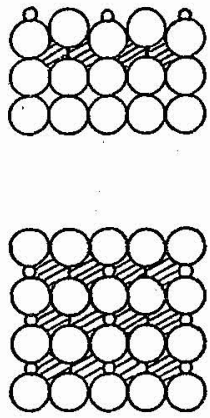

buckled surface
Fig. 3: Different mode1 structures for $(2 \times 1)$ reconstruction on a (110) fcc surface.

surface normal (see Fig. 2 in Ref. 2) yields the following result (Tab. 1): A rigid Ni-substrate (no vertical relaxation) yields a tilt angle of $\delta=330$. Keeping $\delta=O^{0}$ one needs $23 \%$ relaxation between the 1. and 2. $\mathrm{Ni}$ layer. An intermediate fit with $10 \%$ invert relaxation and $\delta=20^{\circ}$ fits the experimental curve reasonably well. This tilt angle $\delta$ towards the $(100)$ facet of the sawtooth may be interesting, if one assumes that 0 chemisorption prefers a (100) face. 
TABLE 1: Experimental values for $R$, amplitude ratios, and calculated amplitude values for different models and orientations. ST and MR denote sawtooth and missing-row models, respectively.

\begin{tabular}{|c|c|c|c|c|c|c|c|c|c|}
\hline \multirow{2}{*}{$\begin{array}{l}\text { Orien- } \\
\text { tation }\end{array}$} & \multirow[b]{2}{*}{$\theta$} & \multirow[b]{2}{*}{$R(\AA)$} & \multirow{2}{*}{$\begin{array}{l}\text { expt. } \\
\text { amplitude } \\
\text { ratio }\end{array}$} & \multicolumn{2}{|c|}{$\begin{array}{c}\text { (a) } \delta=0^{\circ} \\
\text { relax: } 23 \%\end{array}$} & \multicolumn{2}{|c|}{$\begin{array}{l}\text { ampl, ratio } \\
\text { (b) } \delta=20^{\circ}\end{array}$} & \multicolumn{2}{|c|}{$\begin{array}{r}\text { (c) } \delta=33^{\circ} \\
\text { relax: } 0 \%\end{array}$} \\
\hline & & & & $\mathrm{ST}$ & MR & ST & MR & $\mathrm{ST}$ & MR \\
\hline$\left[\begin{array}{l}\infty \\
0 \\
0 \infty 1 \\
0 \infty 1\end{array}\right]$ & $\begin{array}{l}90^{\circ} \\
45^{\circ} \\
20^{\circ}\end{array}$ & $\begin{array}{l}1.85(3) \\
1.87(8) \\
1.88(10)\end{array}$ & $\begin{array}{l}1 \\
0.48(10) \\
0.37(15)\end{array}$ & $\begin{array}{l}1 \\
0.69 \\
0.47\end{array}$ & $\begin{array}{l}1 \\
0.83 \\
0.71\end{array}$ & $\begin{array}{l}1 \\
0.72 \\
0.51\end{array}$ & $\begin{array}{l}1 \\
0.82 \\
0.68\end{array}$ & $\begin{array}{l}1 \\
0.73 \\
0.52\end{array}$ & $\begin{array}{l}1 \\
0.81 \\
0.67\end{array}$ \\
\hline$[110]$ & $90^{\circ}$ & $1.96(8)$ & $0.19(9)$ & 0.19 & 0.38 & 0.16 & 0.30 & 0.14 & 0.27 \\
\hline
\end{tabular}

III. Peak "B" in the Fourier transform

So. far, we have analysed peak "A" only, in Figs. 4 and 1. Evidently a second oscillation or peak can be deduced from the experiment. The backtransformation $\chi(\mathrm{k}) \cdot \mathrm{k}$ in $\mathrm{Fig}$. $4 \mathrm{~b}$ was carried out for 3 windowfunctions, only peak "A" (See Sec. II), only peak "B" yields the high frequency oscillation in $k$, and the sum of the two (dashed dotted line) in Fig. $4 \mathrm{~b}$. It is evident that this follows the experimental curves almost perfectly. The small asymmetry in the experimental oscillation is perfectly reproduced. A priori $O$ and $\mathrm{Ni}$ are as backscatterer possible. Using the experimentally determined $0-0$ phase of $\phi(\mathrm{k})=1.91-0.56 \cdot \mathrm{k} \cdot \AA$ $/ 11 /$, the distance is determined to be 3.37(12) . This is close to the lattice constant $a=3.52 \AA$ and would support the picture that oxygen is alligned along the [001] direction with periodicity "1". Such an analysis has to be taken with caution, since the out-of-plane angle for the O-Ni-O triangle is only $17^{\circ}$. For such a small value a multiple scattering via the $\mathrm{Ni}$ is very likely and limites the accuracy of the determination for the 0-O distance. The O-Ni backscattering phase yields a distance of $3.48(12) \&$. This is closer to the lattice constant, but it is in none of the models (Fig. 3) in agreement to an expected $\mathrm{Ni}$ position. For the $4 \mathrm{th}_{\mathrm{n}} . \mathrm{n}$. one calculates a distance of $4.16 \mathrm{~A}$. A similar analysis has been carried out by A. Puschmann for o(2x1)Cu(110) $15 /$.

If we follow the picture of $0-0$ scattering, we now have to calculate the amplitude ratio for peak $B$ with respect to peak $A$. At $k=5.2 \mathbb{R}^{-1}$, the maximum of $X(k) \cdot k ; F(k)=0.3905(B)$ and 0.4151 (A) / I2/. The $R^{-2}$ term yields a ratio of 0.298 for $B / A$. Finally a mean free path of $\lambda=5 \AA$ (as in the bulk!) again gives a reduction of 0.542 . In total, the $B / A$ amplitude ratio is determined to be 0.13 . The experiment (Fig. 2) yields 0.25 , a factor of two to large. However, it is unrealistic to choose such a short mean free path for the photo-electron wave above the surface layer. Very little is known about real $\lambda$-values for a photoelectron travelling parallel to the substrate surface. If one doubles the path length $(\lambda=10 \AA$, still is a short path), one gains the factor of two, in accord with the experiment.

In conclusion: It is very likely, that peak "B" is due to the backscattering of the oxygen $n . n$. along [001]. But this section demonstrates some limitations of SEXAFS: multiple scattering, phase transferabi1ity, and different $\lambda$-values as function of shell, orientation and $k-$ vector. Moreover, recently Roubin et al. $16 /$ have shown the effect of an anisotropic surface Debye-Waller factor. This complicates the comparison of relative amplitudes, too. 

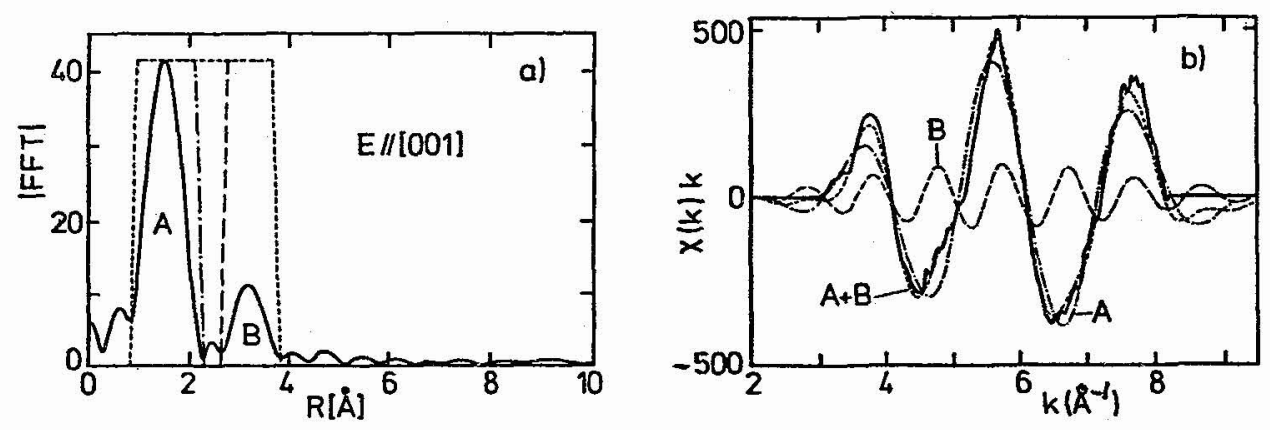

Fig. 4: Fourier transform (same as full line in Fig. 2) and backtransform for 3 different window functions.

IV. The second peak in the Fourier transform in $\mathrm{O} / \mathrm{Ni}$ and $\mathrm{O} / \mathrm{Cu}$

In the introduction we have discussed the simularities between the two systems. Both systems form a (2x1) superstructure under slightly different conditions on the $(110)$ surface. Both systems have been studied by the SEXAFS technique $/ 2,7 /$. In a recent experiment improofed SEXAFS data on $\mathrm{O}(2 \times 1)$ on $\mathrm{Cu}(110)$ at $\mathrm{T}=100 \mathrm{~K}$ and under better conditions of the storage ring BESSY (compared with /7/) were published/3/. In Fig. 5 we reproduce these results: A second peak B* in the FFT is identified for E// [110]. For consistency of the SEXAFS technique and the question of the chemisorption for $1 / 2 \mathrm{ML}$ on $\mathrm{Ni}(110)$ and $\mathrm{Cu}(110)$ we have to face the questions: (i) For $\mathrm{O} / \mathrm{Ni}$ the second backscatterer along the [001] is oxygen, can it be identified for $\mathrm{O} / \mathrm{Cu}$ in $\mathrm{Fig}$. 5? (ii) For $\mathrm{O} / \mathrm{Cu}$ a second peak $\mathrm{B}^{*}$ is due to the $4^{\text {th }} \mathrm{n} \cdot \mathrm{n}$. of $\mathrm{Cu}$. The $3^{\text {rd }} \mathrm{n} \cdot \mathrm{n}$. of $\mathrm{Cu}$ is missing, the authors propose a missing row model for $\mathrm{O}(2 \times 1) /$ $\mathrm{Cu}(110)$. Is the peak $\mathrm{B}^{*}$ detectable for the $\mathrm{O} / \mathrm{Ni}$ system?

(i). We compare the peak B in Fig. 4 with the peak indicated by an arrow in Fig. 5. We feel that they both agree. The oxygen backscattering is also seen for $\mathrm{O} / \mathrm{Cu}$, however the signal-to-noise ratio is smaller by a factor of two. (ii) Peak $B^{*}$ in Fia. 5 is due to the backscattering of the $4^{\text {th }} \mathrm{n} . \mathrm{n}$. in the missing row model. This is the second nearest hashed ball seen from oxygen in Fig. 3 (missing row). Let us assume that the analysis of Sec. II is correct, namely a saw tooth model for $\mathrm{O} / \mathrm{Ni}$. From Fig. 3 we learn, that there exists only one instead of two $\mathrm{Ni}$-atoms in the 4 th shell. Consequently the disappearence of the second peak " $B *$ " for $\theta=90^{\circ}, \phi=90^{\circ}$, in $\mathrm{Fig}$. 2 is a very strong evidence that the type of reconstruction for $\mathrm{O} / \mathrm{N} i$ and $\mathrm{O} / \mathrm{Cu}$ is different. We indicated the $\mathrm{B}^{*}$ position in Fig. 2 by an arrow.

In conclusion : Both SEXAFS experiments on $\mathrm{O} / \mathrm{Cu}$ and $\mathrm{O} / \mathrm{Ni}$ are consistent, if one assumes different types of reconstruction, namely saw tooth for $\mathrm{O} / \mathrm{Ni}$ and missing row for $\mathrm{O} / \mathrm{Cu}$.

\section{Summary}

For the two model systems of $1 / 2 \mathrm{ML} O / \mathrm{Ni}$ and $\mathrm{O} / \mathrm{Cu}$ the SEXAFS technique has proven to give a useful additional information about the local bonding geometry. The limitations for the present analysis have been discussed in Sec. III. The question, why $O(2 \times 1)$ on $N i(110)$ and $C u(110)$ 
induces a different type of reconstruction goes behind the present work. Different mechanisms contribute to the bonding, direct interaction of the $\mathrm{Ni} 3 \mathrm{~d}$-band and the oxygen 2p-orbitals, hybridization between the $\mathrm{Ni} 4 \mathrm{~s} 4 \mathrm{p}$ and oxygen $2 \mathrm{p}$ orbitals, etc. The Cu-3d-orbitals are fully occupied in contrast to the $\mathrm{Ni}-3 \mathrm{~d}$-orbitals. It seems to be commonly accepted that the chemisorption for $\mathrm{O} / \mathrm{Ni}$ is stronger than for $\mathrm{O} / \mathrm{Cu}$. This may be an explanation for the fact that for $\mathrm{O}$ on $\mathrm{Ni}(110)$ in a saw tooth model the local coordination is indeed changed. Whereas for $\mathrm{O}$ on $\mathrm{Cu}(110)$ in a missing row model /3/ the local environment remains the same as on an unreconstructed surface.

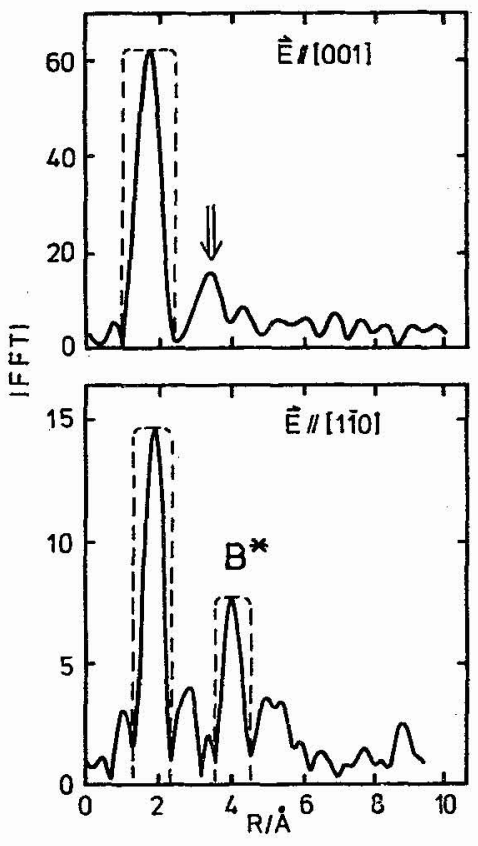

Fig. 5: Fourier transform for two orientations on $(2 \times 1)$ o on $\mathrm{Cu}(110)$ taken from Ref. 3 .

Recently a full multiple scattering (MS) calculation for the near edge structure of $c(2 \times 2) \quad 0 / \mathrm{Cu}(100) / 8 /$ and of $(2 \times 1) \quad 0 / \mathrm{Cu}(110)$ /9/ have been used to determine the local bonding geometry. The good agreement between SEXAFS analysis and NEXAFS-MS result looks promising for this new tool of local structure analysis. In the same way the NEXAFS regimes of our data (Fig. l) were analysed. It turns out that the polar and azimuthal angular dependence is very sensitive on the tilt of oxygen in the bridge position. New experiments with higher energy resolution and better statistics would be needed for a firm answer, however the present analysis $/ 10 /$ agrees with our SEXAFS interpretation using a saw tooth model with tilted oxygen atoms.

The work was supported by BMFT grand nr. 05233 BB.

\section{References}

/1/ A.M. Baro, G. Binnig, H. Rohrer, Ch. Gerber, E. Stoll, A. Baratoff; and F. Salvan, Phys. Rev. Lett. 52, 1304 (1984)

/2/ K. Baberschke, U. Döbler, I. Wenzel, D. Arvanitis, A. Baratoff, K.H. Rieder, Phys. Rev. Rap. Comm. B33, 5910, (1986)

/3/ M. Bader, J. Haase, A. Pushmann, K. F. Frank, BESSY Report (1985)

/4/ For a detailed reasoning and for references of other experimental. work, see ref. 2 .

15/ A. Pushmann, Thesis, FUB (1985), unpublished

/6/ P. Roubin, D. Chandesris, R. Rossi, J. Lecante, M.C. Desjonquères, G. Tréglia, Phys. Rev. Lett 56, 1272 (1986)

/7/ U. Döbler, K. Baberschke, J. Haase, and A. Puschmann, Phys. Rev. Lett. 52,1437 (1984)

18/ D.D. Vvedensky, J. B. Pendry, U. Döbler, K. Baberschke, to be published

19/ U. Döbler, K. Baberschke, D.D. Vvedensky, J.B. Pendry, Ecoss 8 Surf. Sci, (in press)

/10/ D.D. Vvedensky, J.D. Pendry, U. Döbler, K. Baberschke, this conference

/11/ Experimental phase taken from ice, J. Stöhr, priv. communication

112/ B.K. Teo, P.A. Lee, J. Am. Chem. Soc. 101, 2815 (1979) 